\title{
Associations between weight perceptions, weight control and body fatness in a multiethnic sample of adolescent girls
}

\author{
J Scott Duncan*, Elizabeth K Duncan and Grant Schofield \\ Centre for Physical Activity and Nutrition, Auckland University of Technology, Private Bag 92006, Auckland, \\ New Zealand
}

Submitted 13 July 2009: Accepted 13 January 2010: First published online 1 March 2010

\begin{abstract}
Objective: The purpose of the present study was to examine the interactions between weight perceptions, weight control behaviours and body fatness in a multiethnic sample of adolescent girls.

Design: A cross-sectional study.

Setting: Girls from European (37·7\%), Pacific Island (21·6\%), East Asian (15·8\%), Maori $(10 \cdot 2 \%)$ and South Asian (9.6\%) populations and from other ethnicities $(5 \cdot 0 \%)$.

Subjects: A sample of 954 girls aged 11-15 years participated in the study. BMI was derived from height and weight, whereas body fat (BF) was determined from hand-to-foot bioimpedance measurements. Weight perceptions, weight control behaviours and pubertal stage were assessed by questionnaire.

Results: Body size and fatness varied significantly across ethnic groups. Although few differences in weight perceptions were observed between BMI and \%BF percentile groups, a relatively high degree of weight misclassification was evident across all BF categories. The number of girls trying to lose weight exceeded those who perceived themselves as being overweight, with the magnitude of the difference dependent on ethnicity. Of the girls trying to lose weight, the combination of dieting and exercise was the most common weight loss practice; however, a substantial proportion reported neither exercise nor dieting. Weight status perception was a stronger predictor of weight loss intent than actual BF when controlling for all other factors.

Conclusions: Interventions and educational campaigns that assist girls in recognising a state of excess $\mathrm{BF}$ are a priority for all ethnic groups to increase the likelihood that behavioural changes necessary to combat widespread overweight and obesity are adopted.
\end{abstract}

Widespread increases in overweight and obesity have raised the incidence of chronic disease, generating serious public health consequences for many countries. The rapid rise in obesity among young people is particularly alarming given that adolescent obesity tends to persist into adulthood ${ }^{(1,2)}$. Indeed, adolescence has been identified as a critical period for the establishment of lifelong health behaviours ${ }^{(3,4)}$ and is consequently a priority age group for initiatives that promote healthy lifestyles.

The physiological changes that characterise the adolescent years are often accompanied by a heightened awareness of peer approval and social norms. In adolescent girls, external pressures to be slim can raise the importance of body image and weight perceptions in the determination of self-concept, and can lead to the adoption of dieting and exercising for weight control ${ }^{(5,6)}$. However, a number of studies suggest that discordance between perceptions of weight and actual weight status is common in young women ${ }^{(7-11)}$. Misconceptions of body size are of concern given the potential for negative health outcomes: girls who incorrectly perceive themselves to be overweight may face an elevated risk of eating disorders such as anorexia nervosa ${ }^{(12)}$. Conversely, overweight girls who are unable to recognise their condition are unlikely to initiate the lifestyle changes required to obtain a healthy body weight ${ }^{(13)}$. Although both situations are clearly undesirable, given the current prevalence of overweight and obesity the potential to underestimate a state of excessive body fat (BF) presents the greater public health risk.

Earlier efforts to quantify the prevalence and consequences of weight misclassification have been complicated by variation among ethnic groups. Desmond et $a l^{(14)}$ reported that while $100 \%$ of overweight Caucasian girls correctly classified themselves, only $40 \%$ of overweight African American girls recognised their weight status. Similarly, Neumark-Sztainer et al. ${ }^{(11)}$ noted 
that African American adolescent girls were less likely than their Caucasian counterparts to perceive themselves as overweight despite a significantly higher prevalence of overweight. The tendency for adolescent girls of African American descent to misclassify their overweight status was further reinforced by Strauss ${ }^{(13)}$ and Brener et al. ${ }^{(7)}$, the latter authors also observing high rates of misclassification among overweight Hispanic girls. In contrast, ethnic differences in the ability to recognise excess weight were not detected by Simeon et al. ${ }^{(9)}$ in a study of South Asian, African and mixed ethnicity adolescent girls. It should be noted that the majority of literature in this area originates from the United States; issues surrounding weight perceptions in countries with different health-care systems and immigration patterns are poorly understood.

A potential shortcoming of earlier comparisons of weight perceptions and body size in adolescent girls from multiple ethnic groups was the use of universal BMI thresholds to define overweight. The existence of physiological differences in the body composition of girls from different ethnic groups has raised concerns over the appropriateness of existing BMI classification systems. For example, young people of East Asian ${ }^{(15,16)}$, South Asian ${ }^{(16,17)}$ and Hispanic ${ }^{(18,19)}$ descent tend to have more BF than Caucasians at an equivalent BMI. Conversely, Polynesian ${ }^{(16,20)}$ and African American ${ }^{(21)}$ children and adolescents average less BF than their Caucasian counterparts for the same BMI. It is therefore possible that the ethnic differences previously observed in the self-diagnosis of overweight may reflect differences in the accuracy of BMI standards for predicting BF status in diverse populations. Moreover, pubertal development and socio-economic status (SES) may also vary by ethnicity and contribute to the perceptions of overweight in adolescent girls.

Ethnic variation in weight loss practices has also been shown in female adolescents. For example, several studies have shown that African American girls are less likely to diet to lose weight than Caucasian girls ${ }^{(13,14,22)}$. In addition, Neumark-Sztainer et al. ${ }^{(11)}$ reported that Asian American girls were more likely to diet than Caucasian girls. While only one study compared exercise as a weight control practice in different ethnic groups, similar variation was observed among ethnicities: African American girls were less likely to exercise for weight loss than Caucasian girls ${ }^{(14)}$. Despite these differences, a positive association between BMI and weight loss behaviours appears to be a consistent theme across all adolescent girls $^{(13,14,23)}$. Given the limitations of BMI-based weight classification in diverse ethnic groups, comparisons with BF levels may provide a more accurate measure. To our knowledge, the relationship between weight control practices and $\mathrm{BF}$ has yet to be investigated.

An investigation into the weight-related perceptions and practices of young people from different ethnicities is essential for understanding the barriers to initiating behavioural modifications to achieve a healthy body weight and developing targeted interventions. Thus, the purpose of the present study was to examine the interactions between weight perceptions, weight control and body fatness in a multiethnic sample of adolescent girls. The effects of pubertal development and SES on diet and exercise behaviours were also assessed.

\section{Methods}

\section{Participants}

A total of 954 girls aged 11-15 years were randomly selected from eleven intermediate and secondary schools in Auckland, New Zealand. Ethnicity was extracted from demographic information stored within school rolls (originally provided by the caregivers of the child upon enrolment). The ethnic composition of the sample was $37 \cdot 7 \%$ European, $21 \cdot 6 \%$ Pacific Island, $15 \cdot 8 \%$ East Asian, 10.2\% Maori, 9.6\% South Asian and 5.0\% other ethnicities. The East Asian ethnic group included 50.3\% Chinese, 31.1\% Korean, 9.9\% Filipino and 8.6\% other East Asian girls. The South Asian group included 91.3\% Indian, $\mathbf{7 \cdot 6} \%$ Sri Lankan and $1 \cdot 1 \%$ Nepalese. SES was estimated using the Ministry of Education decile classification system for New Zealand schools. Participants from schools with a decile rating of one to three were categorised into the 'LOw' SES group, whereas those from schools rated four to seven and eight to ten were considered 'Middle' and 'High', respectively. Ethical approval for the present study was obtained from the Auckland University of Technology Ethics Committee. A written informed consent was provided by each participant and her legal guardian.

\section{Instruments and procedures}

The height of each participant was measured to the nearest millimetre with a portable stadiometer (Design no. 1013522; Surgical and Medical Products, Seven Hills, Australia). Weight in light clothing without shoes was measured to the nearest $0 \cdot 1 \mathrm{~kg}$ on a digital scale (model Seca 770; Seca, Hamburg, Germany). BMI was calculated as weight divided by squared height $\left(\mathrm{kg} / \mathrm{m}^{2}\right)$. BF measurements were obtained using hand-to-foot bioelectrical impedance analysis (BIA). BIA is a rapid and non-invasive technique for estimating BF that is particularly well suited for use in children. Earlier research has shown that population-specific BIA prediction equations generate valid and reliable estimates of BF in paediatric populations ${ }^{(20,24)}$. Resistance $(R)$ was measured at $50 \mathrm{kHz}$ using a bioimpedance analyser (model BIM4; Impedimed, Capalaba, Australia) with a tetrapolar arrangement of self-adhesive electrodes (Red Dot 2330; 3M Healthcare, St Paul, MN, USA). After swabbing the skin on the right hand and foot with alcohol, source electrodes were 
placed on the dorsal surface of the foot over the distal portion of the second metatarsal, and on the hand on the distal portion of the second metacarpal. Sensing electrodes were placed at the anterior ankle between the tibial and the fibular malleoli, and at the posterior wrist between the styloid processes of the radius and ulna. Testing was initiated after the participants emptied their bladder, and had been lying supine with their arms and legs abducted for at least $5 \mathrm{~min}$. Testing was completed when repeated measurements of $R$ were within $1 \Omega$ of each other. Fat-free mass (FFM) was calculated from $R$, height and weight using two separate ethnic-specific equations previously validated with deuterium dilution in New Zealand children - one specifically for Maori, Pacific Island and European children $\left(r^{2}=0 \cdot 96, \mathrm{SE}=2 \cdot 44 \mathrm{~kg}, \mathrm{CV}=8 \cdot 0 \%\right)^{(19)}$ and another for East and South Asian children $\left(r^{2}=0.98\right.$, $\mathrm{SE}=1.49 \mathrm{~kg}, \mathrm{CV}=5.4 \%)^{(24)}$. The procedures used in the present study, including the BIA instrument, were identical to those used to develop the aforementioned FFM prediction equations. Fat mass (FM) was derived as the difference between FFM and body weight, and percentage BF (\%BF) was calculated as $100 \times \mathrm{FM} /$ weight. Given that there are no generally accepted definitions of adolescent overweight or obesity based on \%BF, age-specific percentiles were used to group the sample according to BF status. Overfat/overweight was defined as a $\% \mathrm{BF}>85$ th percentile in the current sample.

Participants completed a brief survey that included four questions for assessing weight loss practices and weight perceptions: (i) What are you currently trying to do about your weight (Lose weight, Gain weight, Nothing)? (ii) In the last $7 \mathrm{~d}$, did you diet to lose weight (Yes, No)? (iii) In the last $7 \mathrm{~d}$, did you exercise to lose weight (Yes, No)? (iv) What do you currently think about your weight (Underweight, Normal Weight, Overweight)? To determine pubertal stage, participants were presented with a series of Tanner illustrations and asked to identify their level of pubic hair development. This method of pubertal selfassessment shows an acceptable level of agreement with physician assessment in female adolescents from multiple ethnic groups $(r=0 \cdot 86)^{(25)}$. Participants were also asked to provide the date of their first period (if menstruating). On the basis of these data, participants were grouped into four stages of pubertal development: Pre-pubertal (no pubic hair, not menstruating), Early puberty (pubic hair, not menstruating), Late puberty (pubic hair, menstruating for $<24$ months) and Post-pubertal (pubic hair, menstruating for $>24$ months) ${ }^{(26)}$.

\section{Statistical analyses}

Data were analysed using Statistical Package for the Social Sciences statistical software package version $14 \cdot 0$ for Windows (SPSS Inc., Chicago, IL, USA). Differences in participant characteristics (age, height, weight, BMI and \%BF) among ethnic groups were assessed by two-way ANOVA, with significant associations examined by pairwise comparisons using Bonferroni post hoc tests. Logistic regression analysis was used to investigate associations between the frequency of diet and exercise practices and age, ethnicity, SES, pubertal status, weight status and BF perception. Odds ratios for each category were adjusted for all six factors concurrently. Ethnic differences in the frequencies of age and SES categories were examined using $\chi^{2}$ tests.

\section{Results}

Table 1 shows the physical characteristics of the study sample. South Asian girls were slightly younger than the other ethnicities $(P<0 \cdot 05)$. Body size varied across the ethnic groups: Pacific Island girls were the tallest $(P<0 \cdot 05)$, heaviest $(P<0 \cdot 01)$ and had the highest BMI $(P<0 \cdot 01)$, while East and South Asian girls were shorter $(P<0.05)$ and lighter $(P<0.05)$ than the four remaining ethnic groups, and had a lower BMI than Maori and Pacific Island girls $(P<0 \cdot 01)$. South Asian and Pacific Island girls had significantly more BF than European and East Asian $(P<0 \cdot 01)$, and European, East Asian and Maori girls $(P<0 \cdot 05)$, respectively.

Table 2 shows the perceptions of weight status for the selected $\mathrm{BMI}$ and \%BF percentile categories. BMI percentile groups were used instead of other BMI-based definitions of childhood overweight and obesity to enable direct comparisons with the \%BF percentile groups. Overall, the majority of participants considered themselves to be a normal weight. While few differences in weight perceptions were observed between BMI and \%BF percentile groups, there was a relatively high degree of weight misclassification across the distribution. For example, the percentage of girls with a $\% \mathrm{BF}>85$ th percentile who incorrectly perceived themselves to be normal weight or underweight was $39 \cdot 7 \%$ and $4 \cdot 4 \%$, respectively. On the

Table 1 Participant characteristics

\begin{tabular}{|c|c|c|c|c|c|c|c|c|c|c|c|c|c|c|}
\hline & \multicolumn{2}{|c|}{ European ( $n$ 360) } & \multicolumn{2}{|c|}{ Maori ( $n$ 97) } & \multicolumn{2}{|c|}{ Pacific Island ( $n$ 206) } & \multicolumn{2}{|c|}{ East Asian ( $n$ 151) } & \multicolumn{2}{|c|}{ South Asian ( $n$ 92) } & \multicolumn{2}{|c|}{ Other ( $n$ 48) } & \multicolumn{2}{|c|}{ All $(n$ 954) } \\
\hline & Mean & SD & Mean & SD & Mean & SD & Mean & SD & Mean & SD & Mean & SD & Mean & SD \\
\hline & & 0.9 & & $1 \cdot 0$ & & 0.9 & & 1 . & 12 & $1 \cdot$ & $13 \cdot 6$ & $1 \cdot 1$ & $13 \cdot 5$ & $1 \cdot 0$ \\
\hline Height $(\mathrm{cm})$ & $159 \cdot 4$ & $7 \cdot 1$ & $160 \cdot 0$ & $7 \cdot 2$ & $162 \cdot 4$ & $5 \cdot 3$ & $155 \cdot 0$ & $6 \cdot 7$ & $153 \cdot 8$ & $8 \cdot 1$ & $157 \cdot 6$ & 5.9 & $158 \cdot 8$ & $7 \cdot 3$ \\
\hline Weight (kg) & $54 \cdot 4$ & $11 \cdot 6$ & $60 \cdot 0$ & $14 \cdot 9$ & $70 \cdot 1$ & $15 \cdot 8$ & $48 \cdot 7$ & $10 \cdot 1$ & $49 \cdot 2$ & $13 \cdot 5$ & $54 \cdot 0$ & $11 \cdot 0$ & $57 \cdot 0$ & $14 \cdot 9$ \\
\hline BMI $\left(\mathrm{kg} / \mathrm{m}^{2}\right)$ & $21 \cdot 3$ & 3.9 & $23 \cdot 3$ & 4.9 & $26 \cdot 5$ & $5 \cdot 3$ & $20 \cdot 2$ & $3 \cdot 3$ & $20 \cdot 6$ & $4 \cdot 4$ & $21 \cdot 7$ & 3.9 & $22 \cdot 4$ & 4.9 \\
\hline Body fat (\%) & $27 \cdot 4$ & $6 \cdot 4$ & $28 \cdot 5$ & $6 \cdot 3$ & $30 \cdot 9$ & $5 \cdot 9$ & $27 \cdot 4$ & $5 \cdot 2$ & $30 \cdot 4$ & $6 \cdot 6$ & $29 \cdot 5$ & $5 \cdot 7$ & $28 \cdot 7$ & $6 \cdot 3$ \\
\hline
\end{tabular}


Table 2 Number of adolescent girls in each BMI and \%BF percentile category and their self-diagnosis of weight status

\begin{tabular}{|c|c|c|c|c|}
\hline & \multicolumn{3}{|c|}{ Self-diagnosis of weight status } & \multirow[b]{2}{*}{ All $(n 945)$} \\
\hline & Underweight $(n 76)$ & Normal weight ( $n$ 648) & Overweight ( $n$ 221) & \\
\hline \multicolumn{5}{|l|}{ BMI category } \\
\hline$<15$ th percentile & 37 & 102 & 1 & 140 \\
\hline 15-85th percentile & 29 & 497 & 143 & 669 \\
\hline$>$ 85th percentile & 10 & 49 & 77 & 136 \\
\hline \multicolumn{5}{|l|}{ \%BF category } \\
\hline$<15$ th percentile & 17 & 114 & 11 & 142 \\
\hline 15-85th percentile & 53 & 480 & 134 & 667 \\
\hline$>85$ th percentile & 6 & 54 & 76 & 136 \\
\hline
\end{tabular}

$\mathrm{BF}$, body fat.

other hand, $17 \cdot 9 \%$ of girls with a $\% \mathrm{BF}<85$ th percentile believed that they were overweight.

Subsequent analyses revealed that overweight perceptions also differed by ethnicity (European, 20.0\%; Maori, 29.7\%; Pacific Island, 30.1\%; East Asian, 17.3\%; South Asian, $20 \cdot 0 \% ; P<0 \cdot 01)$. Similarly, ethnic variation was observed in the number of girls participating in weight control practices (European, 37.8\%; Maori, 50.0\%; Pacific Island, 65.0\%; East Asian, 43.6\%; South Asian, $37 \cdot 4 \% ; P<0 \cdot 01$ ). Figure 1 presents the differences in overweight perceptions and weight control practices across a range of $\% \mathrm{BF}$ percentile groups. The proportion of girls who consider themselves to be overweight ranged from $0 \%$ to $25 \%$ in the $<15$ th percentile group, and from $48 \%$ to $60 \%$ in the $>85$ th percentile group; the latter finding indicates that many girls who are overweight do not recognise their condition. It is also clear that the number of girls actively trying to lose weight exceeds the number of girls self-diagnosed as overweight, with the extent of the divergence dependent on ethnicity. For example, the proportion of Pacific Island girls who engaged in weight control behaviours was consistently higher than the proportion self-perceived as overweight. In contrast, there was greater agreement between perceptions of overweight and weightloss practices in South Asian girls (with the exception of those in the $>50-85$ th percentile group).

To further investigate weight control practices in this sample, the frequency of dieting and exercising behaviours were compared in girls who were trying to lose weight (Fig. 2). The combination of both dieting and exercise was the most common weight loss practice reported, although a substantial proportion also relied solely on exercise. Interestingly, $16 \cdot 4 \%$ of girls who claimed they were trying to lose weight were neither dieting nor participating in exercise. Ethnic variation was also observed, with Maori girls most likely to combine dieting with exercise and South Asian girls most likely to do neither.

Table 3 displays the unadjusted and adjusted OR for dieting to lose weight within each of the variables assessed in the present study. Unadjusted analyses revealed significant associations between dieting and age, ethnicity, SES, pubertal status, BF status and weight perception. However, ethnicity, BF status and weight perception were the only variables that remained significant after controlling for variation in all other factors. The adjusted data indicate that Pacific Island girls were $1 \cdot 8$ times more likely to diet than European girls, with no significant differences between European girls and any other ethnic group. In addition, participants were more than two times more likely to diet if they had a \%BF $>85$ th percentile. Perception of weight status had the greatest effect on the odds of dieting in this sample, with girls self-diagnosed as overweight more than three times as likely to diet than those who perceived themselves to be underweight.

The odds ratios associated with exercising to lose weight were also calculated (Table 4). The effects of age, ethnicity, pubertal status, BF status and weight perception were significant in the unadjusted model. Age, ethnicity and weight perception remained significant in the fully adjusted model. Older girls were more than twice as likely to participate in exercise as younger girls, and South Asian girls were less likely to exercise than European girls. As with dieting, weight perception showed the strongest association with exercising practices. Girls classified as overfat were also more likely to exercise, although this association was just outside the threshold of statistical significance.

\section{Discussion}

Given the escalating prevalence of youth obesity around the world and the severity of related complications, it is essential that young people are able to recognise a state of excess BF. Indeed, an underestimation of weight status will likely prevent overweight adolescents seeking advice and initiating behavioural changes. The results presented in the present study provide an indication of a mismatch between perceived weight status and actual BF levels in a large proportion of adolescent girls. This builds upon earlier work that investigated such relationships with BMI and/or weight in limited ethnic groups ${ }^{(7-11)}$. Nearly half of the girls with high BF thought that they were normal or underweight, and a reasonable proportion who did not have excess BF thought that they were overweight. 

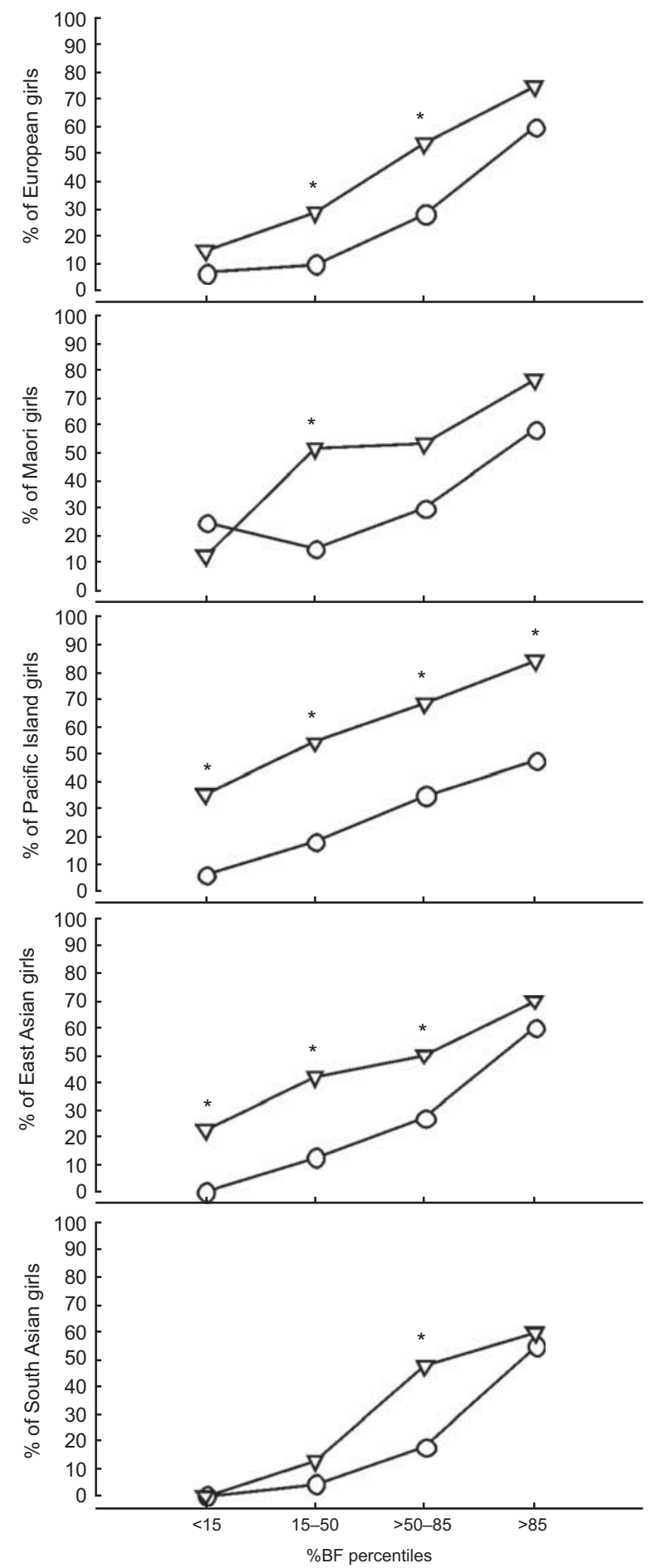

Fig. 1 Perceptions of overweight and the prevalence of weight

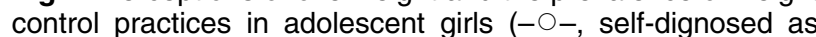
overweight; $-\nabla-$, trying to lose weight). ${ }^{*}$ Significantly different from self-diagnosis of overweight $(P<0.05)$

In addition, there were noticeable differences among ethnicities; the frequency of girls with high BF who did not recognise their condition ranged from $40 \%$ in European and East Asian girls to $52 \cdot 3 \%$ in Pacific Island girls. Such variation in the perception of excess BF may

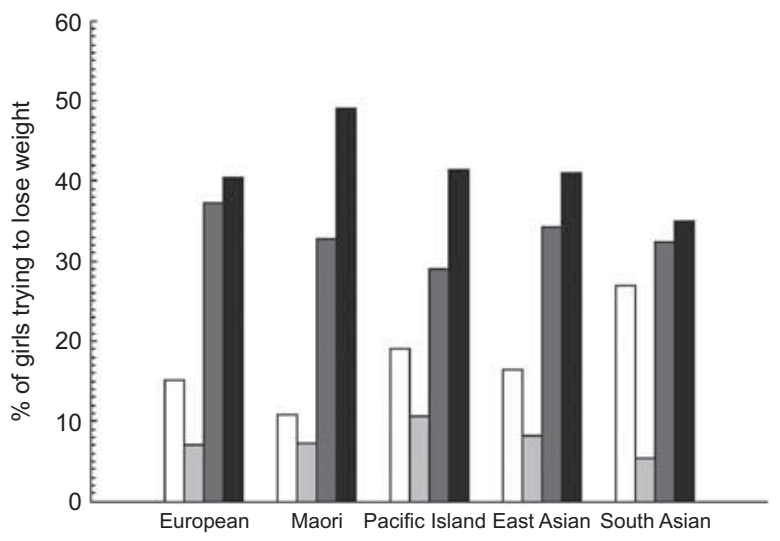

Fig. 2 Prevalence of dieting and exercising in adolescent girls who are trying to lose weight ( $\square$, neither dieting nor exercising; , dieting only; $\square$, exercise only; $\square$, dieting and exercising)

reflect fundamental differences in cultural norms; a large body size can be considered a sign of wealth and prestige in traditional Pacific Island families (although this custom has become diluted in Westernised societies) ${ }^{(27)}$. Thus, being large may not carry the same negative implications in Pacific Island communities than in those from other ethnicities ${ }^{(28)}$. Pacific Island children also have the highest prevalence of BMI-determined obesity of all major ethnic groups in New Zealand ${ }^{(29)}$, which may result in the normalisation of excess $\mathrm{BF}$ in Pacific populations. The identification of ethnic differences in the ability to classify overweight status will assist in prioritising groups for initiatives to improve self-awareness; however, qualitative research into the underlying cultural norms that influence perceptions of body size may be necessary to ensure that such interventions are appropriate for each ethnicity.

The ethnic variation we observed in the underestimation of excess BF is consistent with earlier research using universal BMI standards to define obesity in adolescent girls from multiple ethnic groups ${ }^{(7,11,13,14)}$. Furthermore, the degree of divergence between perceived and measured body size was similar regardless of whether BMI or \%BF percentiles were used. These findings were unexpected given the evidence that BMI is not an equivalent predictor of $\mathrm{BF}$ across multiple ethnicities $^{(15-21)}$. We suggest that these results may reflect the use of weight-related terminology (under-, normal- and overweight) for describing BF status and the closer relationship between these terms and a weight-related index such as BMI when compared with \%BF. Nevertheless, the potential diagnostic error associated with the use of BMI in multiethnic populations does not appear to be a major factor when assessing the perceptions of overweight in adolescent girls.

The results from the present study also revealed that a relatively large proportion of girls who did not perceive themselves as overweight were actively trying to lose weight. This trend may be symptomatic of the firmly 
Table 3 Correlates of dieting to lose weight in adolescent girls

\begin{tabular}{|c|c|c|c|c|c|c|c|c|}
\hline & \multicolumn{4}{|c|}{ Number of participants } & \multirow[b]{3}{*}{ Unadjusted OR } & \multirow[b]{3}{*}{$95 \% \mathrm{Cl}$} & \multirow[b]{3}{*}{ Adjusted* OR } & \multirow[b]{3}{*}{$95 \% \mathrm{Cl}$} \\
\hline & \multicolumn{2}{|c|}{ Non-dieting } & \multicolumn{2}{|c|}{ Dieting } & & & & \\
\hline & $n$ & $\%$ & $n$ & $\%$ & & & & \\
\hline \multicolumn{9}{|l|}{ Age (years) } \\
\hline 11 & 42 & $6 \cdot 2$ & 8 & $3 \cdot 0$ & $1 \cdot 00$ & - & $1 \cdot 00$ & - \\
\hline 12 & 81 & $12 \cdot 0$ & 25 & $9 \cdot 4$ & $1 \cdot 62$ & $0.67,3.90$ & $1 \cdot 25$ & $0.48,3 \cdot 22$ \\
\hline 13 & 205 & $30 \cdot 3$ & 58 & $21 \cdot 8$ & $1 \cdot 49$ & $0 \cdot 66,3 \cdot 34$ & 0.94 & $0 \cdot 37,2 \cdot 41$ \\
\hline 14 & 237 & $35 \cdot 0$ & 110 & $41 \cdot 4$ & $2 \cdot 44$ & $1 \cdot 11,5 \cdot 37 \dagger$ & $1 \cdot 37$ & $0.52,3.58$ \\
\hline 15 & 112 & $16 \cdot 5$ & 65 & $24 \cdot 4$ & $3 \cdot 05$ & $1 \cdot 35,6 \cdot 89 \ddagger$ & $1 \cdot 42$ & $0.52,3.91$ \\
\hline \multicolumn{9}{|l|}{ Ethnicity } \\
\hline European & 278 & $41 \cdot 1$ & 79 & $29 \cdot 7$ & $1 \cdot 00$ & - & $1 \cdot 00$ & - \\
\hline Maori & 66 & $9 \cdot 7$ & 28 & $10 \cdot 5$ & $1 \cdot 49$ & $0 \cdot 90,2 \cdot 48$ & $1 \cdot 22$ & $0 \cdot 65,2 \cdot 29$ \\
\hline Pacific Island & 115 & $17 \cdot 0$ & 86 & $32 \cdot 3$ & $2 \cdot 63$ & $1 \cdot 81,3 \cdot 83 \ddagger$ & $1 \cdot 79$ & $1 \cdot 01,3 \cdot 17 \dagger$ \\
\hline East Asian & 114 & $16 \cdot 8$ & 37 & $13 \cdot 9$ & $1 \cdot 14$ & $0 \cdot 73,1 \cdot 79$ & $1 \cdot 16$ & $0.69,1.93$ \\
\hline South Asian & 76 & $11 \cdot 2$ & 16 & $6 \cdot 0$ & $0 \cdot 74$ & $0 \cdot 41,1 \cdot 34$ & 0.53 & $0 \cdot 26,1 \cdot 10$ \\
\hline Other & 28 & $4 \cdot 1$ & 20 & $7 \cdot 5$ & $2 \cdot 51$ & $1 \cdot 34,4 \cdot 70 \ddagger$ & $2 \cdot 02$ & $0 \cdot 95,4 \cdot 30$ \\
\hline \multicolumn{9}{|l|}{ SES } \\
\hline High & 340 & $50 \cdot 2$ & 116 & $43 \cdot 6$ & $1 \cdot 00$ & - & $1 \cdot 00$ & - \\
\hline Middle & 73 & $10 \cdot 8$ & 20 & $7 \cdot 5$ & $0 \cdot 80$ & $0 \cdot 47,1 \cdot 38$ & $0 \cdot 82$ & $0 \cdot 43,1 \cdot 57$ \\
\hline Low & 264 & $39 \cdot 0$ & 130 & $48 \cdot 9$ & $1 \cdot 44$ & $1.07,1.94 \dagger$ & $1 \cdot 21$ & $0.76,1.93$ \\
\hline \multicolumn{9}{|l|}{ Pubertal status } \\
\hline Pre-pubertal & 28 & $4 \cdot 7$ & 5 & $2 \cdot 2$ & $1 \cdot 00$ & - & $1 \cdot 00$ & - \\
\hline Early puberty & 140 & $23 \cdot 3$ & 34 & $15 \cdot 1$ & $1 \cdot 36$ & $0 \cdot 49,3 \cdot 78$ & $1 \cdot 27$ & $0 \cdot 42,3 \cdot 82$ \\
\hline Late puberty & 298 & $49 \cdot 7$ & 97 & $43 \cdot 1$ & $1 \cdot 82$ & $0 \cdot 69,4.85$ & $1 \cdot 43$ & $0 \cdot 48,4 \cdot 30$ \\
\hline Post-pubertal & 134 & $22 \cdot 3$ & 89 & $39 \cdot 6$ & $3 \cdot 72$ & $1 \cdot 38,10 \cdot 00 \ddagger$ & 1.95 & $0 \cdot 62,6 \cdot 19$ \\
\hline \multicolumn{9}{|l|}{ Body fat status } \\
\hline$<85$ th percentile & 608 & $89 \cdot 8$ & 199 & $74 \cdot 8$ & $1 \cdot 00$ & - & $1 \cdot 00$ & - \\
\hline$>85$ th percentile & 69 & $10 \cdot 2$ & 67 & $25 \cdot 2$ & $2 \cdot 97$ & $2 \cdot 04,4 \cdot 31 \ddagger$ & $2 \cdot 09$ & $1 \cdot 31,3 \cdot 33 \ddagger$ \\
\hline \multicolumn{9}{|l|}{ Weight perception } \\
\hline Underweight & 58 & $8 \cdot 6$ & 18 & $6 \cdot 8$ & $1 \cdot 00$ & - & $1 \cdot 00$ & - \\
\hline Normal weight & 511 & $76 \cdot 0$ & 129 & $49 \cdot 0$ & $0 \cdot 81$ & $0 \cdot 46,1 \cdot 43$ & $0 \cdot 88$ & $0 \cdot 46,1 \cdot 69$ \\
\hline Overweight & 103 & $15 \cdot 3$ & 116 & $44 \cdot 1$ & $3 \cdot 63$ & $2 \cdot 01,6 \cdot 56 \ddagger$ & $3 \cdot 39$ & $1 \cdot 69,6 \cdot 80 \ddagger$ \\
\hline
\end{tabular}

SES, socio-economic status.

${ }^{*}$ Adjusted for all other factors.

tSignificantly different from reference group $(P<0.05)$.

$\ddagger$ Significantly different from reference group $(P<0.01)$.

established societal desire to be slim, a pressure that tends to assume particular importance in adolescent girls ${ }^{(30)}$. With continuous exposure to images and expectations of unrealistic body shapes that promote weight loss regardless of body size ${ }^{(5,6)}$, engaging in unnecessary weight loss practices is perceived as acceptable and even desirable in some adolescent peer groups ${ }^{(31)}$. Another potential explanation is that some non-overweight girls may be persisting with weight loss practices from a period when they were overweight. Our data also clearly indicated that the extent of the divergence between weight perceptions and weight loss practices across the different $\% \mathrm{BF}$ percentiles was dependent on ethnicity. The number of Pacific Island girls trying to lose weight, for example, was consistently higher across all BF categories than the number who considered themselves overweight. This points to an embedded cultural expectation that Pacific Island girls should be trying to lose weight, regardless of their personal perceptions. In contrast, South Asian girls had a high level of agreement between perception and practice in all but the $>50-85$ th percentile group. Together, these findings reinforce the need to communicate weight-related issues with care in adolescent girls, and the importance of tailored approaches for populations with diverse ethnicities and cultures.

An understanding of the behavioural responses to a perception of overweight is valuable for determining acceptable approaches to promote weight loss and achieve a healthy body weight. Of the girls who were attempting to lose weight, the combination of dieting and exercising was the most common weight loss practice reported across all ethnic groups, followed by exercising. This finding suggests that dieting and exercising are both acceptable methods of weight control for adolescent girls from multiple ethnic groups. Interestingly, the number of girls who were trying to lose weight but reported neither dieting nor exercise to do so exceeded those that reported dieting alone. It is also possible that some of the girls who were dieting and or exercising for weight loss may not have done so in the previous $7 \mathrm{~d}$, and thus these behaviours were not picked up in the assessments. Whether this subset of girls are participating in other weight control behaviours or simply recognise their condition but are not motivated to make behavioural changes cannot be determined from the present study. Additional research focusing on the qualitative aspects of 
Table 4 Correlates of exercising to lose weight in adolescent girls

\begin{tabular}{|c|c|c|c|c|c|c|c|c|}
\hline & \multicolumn{4}{|c|}{ Number of participants } & \multirow[b]{3}{*}{ Unadjusted OR } & \multirow[b]{3}{*}{$95 \% \mathrm{Cl}$} & \multirow[b]{3}{*}{ Adjusted ${ }^{*}$ OR } & \multirow[b]{3}{*}{$95 \% \mathrm{Cl}$} \\
\hline & \multicolumn{2}{|c|}{ Non-exercising } & \multicolumn{2}{|c|}{ Exercising } & & & & \\
\hline & $n$ & $\%$ & $n$ & $\%$ & & & & \\
\hline \multicolumn{9}{|l|}{ Age (years) } \\
\hline 11 & 35 & $7 \cdot 4$ & 15 & $3 \cdot 2$ & $1 \cdot 00$ & - & $1 \cdot 00$ & - \\
\hline 12 & 59 & $12 \cdot 5$ & 49 & $10 \cdot 3$ & 1.94 & $0.95,3.96$ & $1 \cdot 76$ & $0 \cdot 81,3 \cdot 80$ \\
\hline 13 & 152 & $32 \cdot 3$ & 113 & $23 \cdot 8$ & $1 \cdot 74$ & $0 \cdot 90,3 \cdot 33$ & $1 \cdot 33$ & $0 \cdot 62,2 \cdot 85$ \\
\hline 14 & 153 & $32 \cdot 5$ & 194 & $40 \cdot 8$ & $2 \cdot 96$ & $1 \cdot 56,5 \cdot 62 \ddagger$ & $2 \cdot 34$ & $1 \cdot 06,5 \cdot 15 \dagger$ \\
\hline 15 & 72 & $15 \cdot 3$ & 104 & $21 \cdot 9$ & $3 \cdot 37$ & $1 \cdot 72,6 \cdot 62 \ddagger$ & $2 \cdot 09$ & $0 \cdot 90,4 \cdot 85$ \\
\hline \multicolumn{9}{|l|}{ Ethnicity } \\
\hline European & 190 & $40 \cdot 3$ & 165 & $34 \cdot 7$ & $1 \cdot 00$ & - & $1 \cdot 00$ & - \\
\hline Maori & 49 & $10 \cdot 4$ & 47 & $9 \cdot 9$ & $1 \cdot 11$ & $0 \cdot 70,1 \cdot 73$ & 0.93 & $0 \cdot 55,1 \cdot 59$ \\
\hline Pacific Island & 77 & $16 \cdot 3$ & 127 & $26 \cdot 7$ & $1 \cdot 90$ & $1 \cdot 34,2 \cdot 70 \ddagger$ & $1 \cdot 43$ & $0 \cdot 85,2 \cdot 39$ \\
\hline East Asian & 73 & $15 \cdot 5$ & 78 & $16 \cdot 4$ & $1 \cdot 23$ & $0 \cdot 84,1 \cdot 80$ & $1 \cdot 16$ & $0 \cdot 75,1 \cdot 77$ \\
\hline South Asian & 58 & $12 \cdot 3$ & 34 & $7 \cdot 2$ & $0 \cdot 68$ & $0 \cdot 42,1 \cdot 08$ & 0.54 & $0.31,0.95 t$ \\
\hline Other & 24 & $5 \cdot 1$ & 24 & $5 \cdot 1$ & $1 \cdot 15$ & $0 \cdot 63,2 \cdot 11$ & $0 \cdot 89$ & $0 \cdot 44,1 \cdot 78$ \\
\hline \multicolumn{9}{|l|}{ SES } \\
\hline High & 234 & $49 \cdot 7$ & 219 & $46 \cdot 1$ & $1 \cdot 00$ & - & $1 \cdot 00$ & - \\
\hline Middle & 50 & $10 \cdot 6$ & 43 & $9 \cdot 1$ & 0.92 & $0 \cdot 59,1 \cdot 44$ & 0.95 & $0.57,1 \cdot 58$ \\
\hline Low & 187 & $39 \cdot 7$ & 213 & $44 \cdot 8$ & $1 \cdot 22$ & $0.93,1.59$ & $1 \cdot 28$ & $0 \cdot 86,1 \cdot 92$ \\
\hline \multicolumn{9}{|l|}{ Pubertal status } \\
\hline Pre-pubertal & 19 & $4 \cdot 6$ & 14 & $3 \cdot 4$ & $1 \cdot 00$ & - & $1 \cdot 00$ & - \\
\hline Early puberty & 113 & $27 \cdot 1$ & 61 & $14 \cdot 9$ & $0 \cdot 73$ & $0 \cdot 34,1 \cdot 56$ & 0.64 & $0 \cdot 28,1 \cdot 43$ \\
\hline Late puberty & 198 & $47 \cdot 5$ & 198 & $48 \cdot 4$ & $1 \cdot 36$ & $0 \cdot 66,2 \cdot 78$ & 0.96 & $0 \cdot 43,2 \cdot 15$ \\
\hline Post-pubertal & 87 & $20 \cdot 9$ & 136 & $33 \cdot 3$ & $2 \cdot 12$ & $1 \cdot 01,4 \cdot 45 t$ & $1 \cdot 07$ & $0 \cdot 45,2 \cdot 54$ \\
\hline \multicolumn{9}{|l|}{ Body fat status } \\
\hline$<$ 85th percentile & 423 & $89 \cdot 8$ & 386 & $81 \cdot 3$ & $1 \cdot 00$ & - & $1 \cdot 00$ & - \\
\hline$>85$ th percentile & 48 & $10 \cdot 2$ & 89 & $18 \cdot 7$ & $2 \cdot 03$ & $1 \cdot 39,2 \cdot 96 \ddagger$ & 1.57 & $0 \cdot 99,2 \cdot 48$ \\
\hline \multicolumn{9}{|l|}{ Weight perception } \\
\hline Underweight & 45 & $9 \cdot 6$ & 31 & $6 \cdot 6$ & $1 \cdot 00$ & - & $1 \cdot 00$ & - \\
\hline Normal weight & 350 & $74 \cdot 9$ & 292 & $62 \cdot 0$ & $1 \cdot 21$ & $0 \cdot 75,1 \cdot 96$ & $1 \cdot 24$ & $0 \cdot 71,2 \cdot 14$ \\
\hline Overweight & 72 & $15 \cdot 4$ & 148 & $31 \cdot 4$ & $2 \cdot 98$ & $1 \cdot 74,5 \cdot 11 \ddagger$ & $2 \cdot 52$ & $1 \cdot 35,4 \cdot 71 \ddagger$ \\
\hline
\end{tabular}

SES, socio-economic status.

${ }^{*}$ Adjusted for all other factors.

+Significantly different from reference group $(P<0.05)$.

$\ddagger$ Significantly different from reference group $(P<0 \cdot 01)$.

approaches to weight loss would be helpful for understanding why a particular behaviour was initiated.

A potential limitation of the present study was the selfassessment of pubertal status. Clearly, the criterion method is assessment by a trained physician; however, the ethical issues surrounding the undressing of adolescent girls precludes the use of this technique in population research. We suggest that the use of Tanner illustrations - validated previously in a multiethnic sample of female adolescents ${ }^{(25)}$ is the most suitable alternative to physical assessment, providing participants with standardised visual cues with which to judge their pubertal development. It should also be noted that the questions used to determine weight perceptions in the present study were not validated due to the lack of practical criterion measures for determining weight control practices and perceptions.

The present study is the first to investigate both dieting and exercise practices for weight loss and to compare these with measurements of $\mathrm{BF}$ and weight perceptions in multiple ethnic groups. Although participants were more likely to be exercising or dieting to lose weight if they were classified as overfat, our results indicate that an individual's weight status perception was a stronger predictor of weight loss intent than actual $\mathrm{BF}$, when controlling for all other factors. This finding shows that self-diagnostic inaccuracies in classifying weight status would be likely to flow on to weight control behaviours, and thus, the importance of educating girls about how to correctly classify their body size. While ethnic and age variation in the frequency of dieting and exercise was also observed, the effects of SES and pubertal status were only significant when analysed separately.

\section{Conclusions}

Overall, adolescent girls from a diverse range of ethnic groups tended to be poor at accurately classifying their weight status. The presence of weight misclassification across the range of $\mathrm{BF}$ categories (normal weight girls perceiving themselves as overweight and girls with high $\mathrm{BF}$ perceiving themselves as normal or underweight) shows the conflicting issues of body size perceptions that exist in this group. Thus, interventions in this subgroup of the population should focus on delivering clear, consistent messages that promote a healthy weight rather 
than simply weight loss. With regard to weight loss practices, evidence of strong positive relationships between measured BF status and the frequency of weight loss practices across all ethnic groups was promising. However, given that perceived weight status was more strongly associated with dieting and exercising behaviours, and that a substantial proportion of girls were unable to correctly classify themselves as overweight, educational programmes that assist girls in recognising a state of excess $\mathrm{BF}$ are a priority to increase the likelihood that behavioural changes necessary to combat widespread overweight and obesity are adopted.

\section{Acknowledgements}

The present study was supported by project grants from Sport and Recreation New Zealand and the School of Sport and Recreation, Auckland University of Technology. All authors were involved in the conception and design of the study. J.S.D. and E.K.D. were responsible for data collection and statistical analyses. All authors contributed to writing and approved the final manuscript. The authors have no conflicts of interest to declare.

\section{References}

1. Power C, Lake JK \& Cole TJ (1997) Measurement and longterm health risks of child and adolescent fatness. Int J Obes Relat Metab Disord 21, 507-526.

2. Kvaavik E, Tell GS \& Klepp KI (2003) Predictors and tracking of body mass index from adolescence into adulthood: follow-up of 18 to 20 years in the Oslo Youth Study. Arch Pediatr Adolesc Med 157, 1212-1218.

3. Must A \& Strauss RS (1999) Risks and consequences of childhood and adolescent obesity. Int J Obes Relat Metab Disord 23, S2-S11.

4. Berkey CS, Rockett HR, Field AE et al. (2000) Activity, dietary intake, and weight changes in a longitudinal study of preadolescent and adolescent boys and girls. Pediatrics 105, E56.

5. McVey G, Tweed S \& Blackmore E (2005) Correlates of weight loss and muscle-gaining behavior in 10- to 14-yearold males and females. Prev Med 40, 1-9.

6. Field AE, Camargo CA Jr, Taylor CB et al. (2001) Peer, parent, and media influences on the development of weight concerns and frequent dieting among preadolescent and adolescent girls and boys. Pediatrics 107, 54-60.

7. Brener ND, Eaton DK, Lowry R et al. (2004) The association between weight perception and BMI among high school students. Obes Res 12, 1866-1874.

8. Lee K, Sohn H, Lee S et al. (2004) Weight and BMI over 6 years in Korean children: relationships to body image and weight loss efforts. Obes Res 12, 1959-1966.

9. Simeon DT, Rattan RD, Panchoo K et al. (2003) Body image of adolescents in a multi-ethnic Caribbean population. Eur J Clin Nutr 57, 157-162.

10. Gillison FB, Standage M \& Skevington SM (2006) Relationships among adolescents' weight perceptions, exercise goals, exercise motivation, quality of life and leisure-time exercise behaviour: a self-determination theory approach. Health Educ Res 21, 836-847.
11. Neumark-Sztainer D, Croll J, Story M et al. (2002) Ethnic/ racial differences in weight-related concerns and behaviors among adolescent girls and boys: findings from Project EAT. J Psychosom Res 53, 963-974.

12. Wakeling A (1996) Epidemiology of anorexia nervosa. Psychiatry Res 62, 3-9.

13. Strauss RS (1999) Self-reported weight status and dieting in a cross-sectional sample of young adolescents: National Health and Nutrition Examination Survey III. Arch Pediatr Adolesc Med 153, 741-747.

14. Desmond SM, Price JH, Hallinan C et al. (1989) Black and white adolescents' perceptions of their weight. $J$ Sch Health 59, 353-358.

15. Deurenberg P, Deurenberg-Yap M, Foo LF et al. (2003) Differences in body composition between Singapore Chinese, Beijing Chinese and Dutch children. Eur J Clin Nutr 57, 405-409.

16. Duncan JS, Duncan EK \& Schofield G (2009) Accuracy of body mass index (BMI) thresholds for predicting excess body fat in girls from five ethnicities. Asia Pac J Clin Nutr 18, 404-411.

17. Mehta S, Mahajan D, Steinbeck KS et al. (2002) Relationship between measures of fatness, lipids and ethnicity in a cohort of adolescent boys. Ann Nutr Metab 46, 192-199.

18. Ellis KJ (1997) Body composition of a young, multiethnic, male population. Am J Clin Nutr 66, 1323-1331.

19. Ellis KJ, Abrams SA \& Wong WW (1997) Body composition of a young, multiethnic female population. Am J Clin Nutr 65, 724-731.

20. Rush EC, Puniani K, Valencia ME et al. (2003) Estimation of body fatness from body mass index and bioelectrical impedance: comparison of New Zealand European, Maori and Pacific Island children. Eur J Clin Nutr 57, 1394-1401.

21. Daniels SR, Khoury PR \& Morrison JA (1997) The utility of body mass index as a measure of body fatness in children and adolescents: differences by race and gender. Pediatrics 99, 804-807.

22. Field AE, Aneja P, Austin SB et al. (2007) Race and gender differences in the association of dieting and gains in BMI among young adults. Obesity (Silver Spring) 15, 456-464.

23. Field AE, Austin SB, Taylor CB et al. (2003) Relation between dieting and weight change among preadolescents and adolescents. Pediatrics 112, 900-906.

24. Duncan EK, Rush EC, Duncan JS et al. (2007) Validity of bioelectrical impedance for predicting fat-free mass in Chinese and Indian children. Int J Body Compos Res 5, $17-25$.

25. Neinstein LS (1982) Adolescent self-assessment of sexual maturation: reassessment and evaluation in a mixed ethnic urban population. Clin Pediatr (Phila) 21, 482-484.

26. Murdey ID, Cameron N, Biddle SJ et al. (2004) Pubertal development and sedentary behaviour during adolescence. Ann Hum Biol 31, 75-86.

27. Craig PL, Swinburn BA, Matenga-Smith T et al. (1996) Do Polynesians still believe that big is beautiful? Comparison of body size perceptions and preferences of Cook Islands, Maori and Australians. N Z Med J 109, 200-203.

28. Brewis AA, McGarvey ST, Jones J et al. (1998) Perceptions of body size in Pacific Islanders. Int J Obes Relat Metab Disord 22, 185-189.

29. Ministry of Health (2008) A Portrait of Health: Key Results of the 2006/07 New Zealand Health Survey. Wellington: Ministry of Health.

30. Stice E, Spangler D \& Agras WS (2001) Exposure to mediaportrayed thin-ideal images adversely affects vulnerable girls: a longitudinal experiment. J Soc Clin Psychol 20, 270-288.

31. Neumark-Sztainer D \& Hannan PJ (2000) Weight-related behaviors among adolescent girls and boys: results from a national survey. Arch Pediatr Adolesc Med 154, 569-577. 